\title{
Developing family-friendly signage in a South African paediatric healthcare setting
}

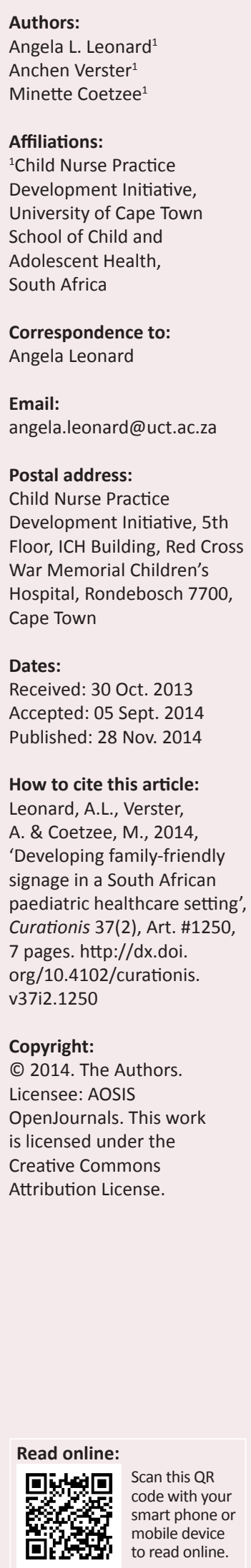

Background: Multiple renovations and changing flow in a tertiary children's hospital in Cape Town resulted in numerous signs being posted in the corridors and units, making wayfinding extremely complex. A request from nursing management prompted the formation of a learning collaborative of nurses from all departments to improve wayfinding signage.

Objectives: The project aimed to contribute to a family-friendly environment by reviewing the current situation and developing signage to improve wayfinding and convey essential information to parents, caregivers and patients.

Methods: A participative action research method followed a four-stage process to facilitate the development of family-friendly signage. Nurse participants reviewed existing signage and collaboratively developed new signage templates and posted signs. The signage was then evaluated using a rapid appraisal questionnaire involving 50 parents and nurse respondents. At each stage of data collection, thematic content analysis was used to analyse data gathered in process meetings and the reflections of participating nurses.

Results: A design template and then 44 new signs were developed and used to replace old signage. Respondents reported that the new signs were noticeable, looked attractive and were easily understandable.

Conclusion: Intentional and active participation of nurses in clinical paediatric settings ensured collaborative data gathering and analysis. An inclusive research design allowed for insights into the words and tone of posted signs that nurse participants had not noticed previously. The participative redesign of signage resulted in a sense of ownership of the signs. The support and involvement of hospital management throughout ensured that the resulting signage received wide acceptance.

\section{Introduction}

The hospitalisation of a child is a stressful time, not only for the child but also for the family (Commodari 2010). Parents and children often enter healthcare settings, an unfamiliar space, with little or no prior warning or preparation. In facilities undergoing construction and renovations, changes in patient flow and temporary accommodation may add to this stress and confusion. Nurses and other staff direct parents and children around the wards and facility on a daily basis. Parents rely on these directions to find their way and to make the context less daunting. A familyfriendly environment contributes to the patient and family experience and is important with regard to helping parents overcome the stress of their child's hospitalisation.

\section{Problem statement}

Multiple renovations and changing flow in units at a tertiary children's hospital in Cape Town resulted in frequent questions from parents that led the nurses to post numerous makeshift signs on the unit and corridor walls in an attempt to answer these questions. Despite this, nurses expressed frustration at the time still required to direct and orient parents in the facility. The development of visible, attractive and understandable signage was identified as a means to align clinical practice with a family-friendly approach.

\section{Aims of the study}

The aim of this study was to develop family-friendly signage to inform and facilitate wayfinding in and around the paediatric departments in a large, tertiary children's hospital in Cape Town, South Africa.

The study's objectives included:

1. Review of existing signage in the healthcare setting. 
2. Participative design of appropriate signage to facilitate wayfinding and contribute to a more familyfriendly environment.

3. Approval, printing and posting of new signage.

4. Involvement of parents and staff in the review and evaluation of the new signage.

\section{Background}

As a nation, South Africa encompasses a diverse richness of origins, cultures, social backgrounds, languages and religious beliefs. There are 11 official languages and English is the home language of a minority of the population (8\%) (Statistics South Africa 2012). Families and children at the tertiary children's hospital in which the research was done reflect this demography and speak mostly one of three languages: Afrikaans, isiXhosa and English.

The hospital has both inpatient and outpatient facilities. Each year, along with approximately 800 trauma patients, the hospital admits 30000 children and sees approximately 3000 children in need of emergency medical care. The facility serves a busy metropolitan area with a rapidly-urbanising population. Referrals for sub-specialist care come from throughout South Africa.

\section{Literature review Family-friendly approach}

A family-friendly environment places families and their children, rather than the healthcare provider's needs, at its centre. Both family-friendly and family-centred care operate on the premise that the child is an integral part of a family and thus includes the family's needs in the care that is given (Frazier, Frazier \& Warren 2010). The environment in which a family-friendly approach occurs adopts policies and practices that create intentional support and collaboration between families and staff (IBM Global Work/Life Fund 2004).

\section{Signage contributes to a family-friendly environment}

Strong signage sets the stage for a family-friendly environment and contributes to the positive patient experience (Montpetit 2013). A priority for caregivers when arriving at a hospital with a sick child is being able to locate the signs that indicate the direction in which they should go to receive attention.

Clear signs that assist families in finding their way can decrease stress and anxiety and increase patient satisfaction. Getting lost in a hospital adds to anxiety levels and this, in turn, can contribute to staff burden, as staff members spend additional time redirecting patients. The added time spent redirecting patients and families, in a large hospital specifically, is reported to be the equivalent of 10 additional hours per patient bed per year (Arthur \& Passini 2002).

The Institute of Healthcare Improvement (IHI) maintains that, in addition to 'no needless deaths', 'no needless injury' and 'no needless waste' (IHI 2003:5), indicators of healthcare quality include: no needless waiting, no needless helplessness, and no-one left out. This quality directive includes children, their families or healthcare providers and speaks clearly to the importance of patient experience in the provision of quality care. Improved wayfinding and signage designed by nurses and evaluated by parents could help prevent needless waiting and feelings of helplessness in patients and parents.

\section{Information transfer for family-friendly communication}

Transfer of information can be verbal or written. Kain et al. (1996) state that the verbal, 'one-to-one' transfer of information may be most effective. The shortcoming of verbally-communicated information, especially directions given in passing, is that it is easily forgotten or misinterpreted (Scott 2004) and may add to confusion. The benefit of easyto-read, written or printed communication is that parents are able to absorb information at their own pace (McKenna $\&$ Scott 2007). The information, once in a written format, is standardised (Jackson et al. 2008) and easier to follow. In relation to signage, parents can return to the last sign they encountered for clarification in their wayfinding, or easily 'pick up the trail' by recognising the appearance of the next wayfinding sign to guide them further. In a children's hospital, for example, coloured bands painted along the top of the corridors could be followed easily in order to find a location; these take the form of, for example, blue bands that indicate the way to radiology, or pink bands to the pharmacy.

\section{Effective signage}

Effectiveness of signage design depends on the hospital's configuration, size and service population (Cooper 2010). Effective signage is eye-catching and recognisable; it directs or informs visitors in a convenient manner (Rousek \& Hallbeck 2011). In a healthcare setting, signs instruct visitors as to where they are and direct them to other parts of the hospital; they also describe hospital rules and policies, such as visiting hours (Mollerup 2009). The quantity of information in a healthcare setting can be overwhelming to visitors (Cooper \& Smith 2004), so signage should be concise.

Furthermore, all signage should be inter-related through a common design theme (Cooper \& Smith 2004). To communicate their message effectively, signs must be visible and accessible. Mollerup (2009) recommends that signs should be brightly coloured, to make them stand out from their background, saying that text should be in a contrasting colour to make it readable. Houts et al. (2006) furthermore reported that the effectiveness of health communication is increased by including images or graphics in the design.

In the study context of a busy paediatric clinical service that was undergoing constant building upgrades and experiencing a high patient load, signs needed to be clear in order to convey the necessary information in ways that were effective for this patient population and staff. 


\section{Research methods and design Research approach and method}

A participatory action research approach was used to guide the development, implementation and evaluation of family-friendly signage. The research process consisted of four stages and used a rapid appraisal questionnaire to evaluate signs four weeks after these had been posted.

Action research is defined as a methodology 'working toward practical outcomes and creating new forms of understanding, to produce practical knowledge that is useful to people in the everyday conduct of their lives' (Reason \& Bradbury 2001:2). The action research process involves cycles of planning, implementing and evaluation (Coghlan \& Casey 2001). In the context of this study, nurse participants worked together to generate ways of contributing to a family-friendly environment and tackled the problems relating to ad hoc signage within the facility.

Nurse participants worked together to review current signage, inform project design, propose methods, facilitate some of the project activities and review the process activities that are all aligned with the process of action research as described by Mackenzie and colleagues (2012). Whilst participatory action research seeks to understand human experiences, it further 'goes beyond understanding to taking constructive action' (Olshansky et al. 2005:122). In this setting, the approach was used to go beyond understanding why the staff posted ad hoc and makeshift signs; rather it enrolled nurses in order to gain an understanding of their current situation and to ensure their participation with regard to planning the outcomes of the study - namely, the development of attractive signage for directing families. The four stages of the design are described in Figure 1.

\section{Population and sampling}

The IHI describes a core participative approach for working in large organisations as a 'learning collaborative'. This

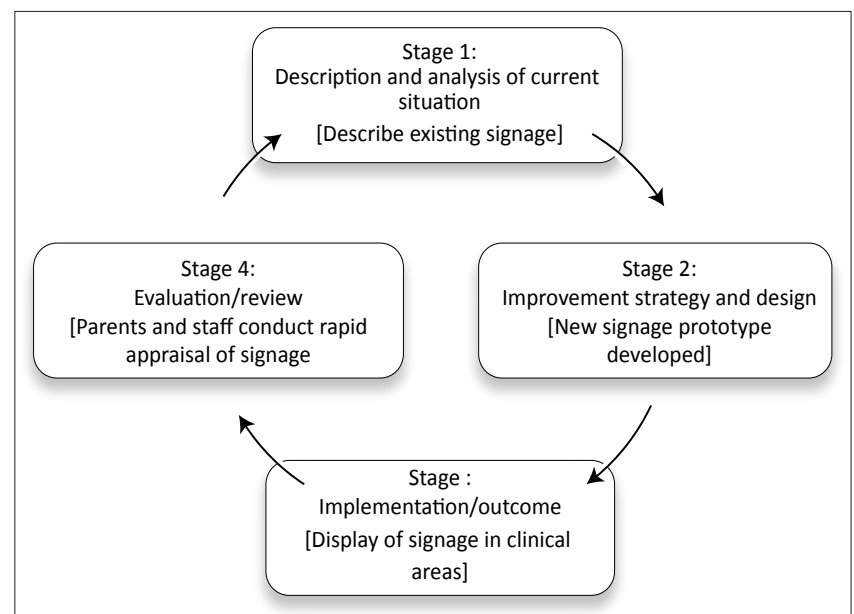

Source: Institute for Healthcare Improvement, 2003, 'The breakthrough series: IHI's collaborative model for achieving breakthrough improvement', IHI Innovation Series white paper, viewed 18 April 2014, from http://www.ihi.org/resources/Pages/IHIWhitePapers/ TheBreakthroughSeriesIHIsCollaborativeModelforAchievingBreakthroughImprovement.aspx FIGURE 1: Action research process followed to develop family-friendly signage short-term learning system brings together teams working on the same focused topic for a set number of months (IHI 2003). The IHI developed the approach so as to facilitate active participation across an entire healthcare facility and to bring about improvement to practice.

With the help of the lead researchers, participant groups of nurses from within the units and departments of the hospital formed a learning collaborative to create a more familyfriendly environment across the whole facility. An operational team from within this group managed the research process and maintained accountability to the collaborative. This core team consisted of two nurses (the operational manager and one registered nurse) from each unit and three researchers of the Child Nurse Practice Development Initiative (CNPDI). Parents were only involved directly in the evaluation of signage once the signs had been posted. Evaluation was provided by two groups: one comprising 25 parents and the other, 25 nurses. Neither of these groups had any direct involvement in the design and preparation of the signage.

\section{Data collection}

After obtaining institutional permission, the operational team photographed all the existing signage in the hospital. These were analysed collaboratively for themes, which directed the design of the new signs. New sign templates were designed and taken back to ward-level for comments and recommended refinement. Specific data gathering at ward level of opinions regarding the effectiveness of the new sign template was not directed or directly observed by the researchers; individual nurses were instead left to elicit ward-level participation at their discretion. Some nurses reported involving colleagues, some approached doctors and a number reported that they had elicited the opinions of parents in the ward at the time. These refined perspectives contributed to the redesigned templates and were added to the data set.

Nurse participants in the core team met every fortnight to review progress and plan their next actions. At each meeting, represented ward teams also reported on their activities, progress and lessons they had learned. Progress notes and activities undertaken at unit level were tracked along with discussions and recorded as data. These notes were collated along with the research decisions for the next fortnight's activities. Activities during the course of the study included the initial collaborative review and design of signs, reaching consensus, translation of signs into three languages, proofing, planning, printing and posting (or displaying) of signs. Once these activities were completed, the evaluation was planned and administered and data were analysed.

After the final templates were reviewed and accepted by hospital management, signs were printed and posted. A rapid appraisal questionnaire was designed in order to elicit evaluations from staff and families. 


\section{Rapid appraisal}

Rapid appraisal identifies, collects and analyses information about a problem in a short period of time, in order to gain specific information. Annett and Rifkin (1988) describe the characteristics of rapid appraisals as follows:

- Not too much data and no irrelevant data is collected, but just enough to see and/or direct the change;

- designed/adjusted to reflect local conditions and the specific situation; and

- involving community perspectives in defining or responding to local needs.

Murray (1999) adds that rapid appraisals assist in identifying possible solutions and translating these findings into practice. They provide information for decision-making, and provide qualitative understanding and context from a specific group of people (World Bank 2004). The rapid appraisal questionnaires were designed to obtain specific information guided by analysis of photographs of original signage, which indicated what participants wanted to change. These rapid appraisals were administered to 50 respondents (25 nurses and 25 parents of children in hospital). The appraisal was not designed to gather data about signs that were generalisable to other contexts, but rather to assess whether these signs contributed in some way to a more family-friendly environment in the hospital.

The short, rapid appraisal questionnaire consisted of the following five questions. The first required a yes/no response, the next three required responses on a five-point Likert scale and the last question provided opportunity for an open response:

- Have you seen and read any of the new signs? [To assess visibility of signage]

- Are the yellow signs easy to understand? [To hear perceptions of the clarity of the information]

- Do the yellow signs look attractive? [Perceptions of how eye-catching the signs are]

- Do you find the yellow signs helpful? [To see if signs direct or inform people in a convenient manner]

- Any suggestions? [To give opportunity for additional contribution]

\section{Data treatment}

All data, including initial visual analysis of existing signage, progress and research notes, progressive versions of signage templates and signage and evaluation data, were transcribed, stored electronically, backed up and password protected.

At each stage of data collection, collaborative thematic content analysis was used to guide the next research phase and development process. Data analysis and interpretation of results were subjected to peer review within the learning collaborative.

\section{Results}

\section{Action research cycle}

Stage 1: Description and analysis of current situation

At their first meeting, the learning collaborative agreed to conduct a full review of current signage at the hospital. Initial analysis revealed that the facility walls had many displayed signs in various stages of disrepair, or hand-written on recycled paper and which lacked uniformity. The operational team analysed the photographed signs and divided these into two categories: 'wayfinding' signs and 'messages of information' (including signs with instruction to parents, such as where to collect something, where not to brush their teeth or where to recharge a mobile phone). Analysis revealed that the overall tone of the information signs was instructive. Most of these signs featured the words 'no' and 'don't', telling children and families what not to do.

Numerous signs displayed on walls amidst health education and other posters meant that signs directing patient flow were sometimes lost amongst the rest of the posted information in corridors and waiting rooms. Signs were often posted in obscure places and most were in English, which is not the primary language of the majority of families visiting the hospital. There was little evidence of colour usage or the inclusion of eye-catching, visual elements.

Nurse participants expressed surprise at the tone and appearance of the existing signage. Some expressed embarrassment about how their 'place looks and sounds to people'.

The process of analysing and reporting findings to the bigger group elicited lively conversations regarding assisting families who were seen looking lost and struggling to find their way around the hospital.

\section{Stage 2: Improvement strategy and design}

The second action research stage entailed design, development and acceptance of a new signage template, as well as acceptance of its content. Based on analysis of existing signs, the research team decided that redesigned signage should display a clear message in three languages, be visually appealing and should then be placed strategically so as to be both visible and helpful.

The research team distilled the essential messages using intentional empathic words in an active voice. The word 'no' was replaced with 'please' and signs were rephrased so as to invite cooperation. The wording was made less prescriptive and conveyed a more family-friendly tone. The collaborative design process yielded a series of templates. These were refined further after team members obtained additional input from their ward staff. It quickly became apparent that revised signs would have to be colourful, visually appealing and required professional translation.

Following consensus on wording, signs were translated into three of the main Western Cape languages: English, Afrikaans and isiXhosa. Back-translation by an independent local language expert confirmed that the meaning and positive tone were retained. The operational team completed the initial redesign of the templates using Microsoft ${ }^{\circledR}$ 
PowerPoint. Signs included a visual element, such as an icon or picture inside a circle, placed under the text, to convey the message visually. A tick symbol or a cross symbol was added to catch the parents' attention. Nursing management reviewed the revised signage and suggested that adding a single bright colour to the background of the signs would standardise signs and make them more eye-catching. Uniformity of the signage throughout the hospital was provided by changing the background from white to bright yellow (Figure 2). The head of infection control at the hospital suggested including content on methods to minimise the spread of infection. The signs were laminated to reduce infection risks and ensure durability.

\section{Stage 3: Implementation/outcome}

Stage three of the action research cycle involved selecting the most appropriate signs for each unit and clinical areas, planning the best position for signs and then posting them.

The head nurse of each unit received a list of all 44 sign designs, along with an order form and a sample sign. The head nurses selected the signs they required for their units. Existing signs and information notices were removed and replaced by the new signs. Information and health education posters were grouped on notice boards in an attempt to alleviate the clutter of posted information.

\section{Stage 4: Evaluation/review}

One week after the revised signage had been delivered to the respective wards, the operational team followed up with each head nurse to confirm that (s)he had both received and posted the signs. Opportunity was also provided for the head nurses to raise any concerns and queries for addressing.

Four weeks after posting the new signs, the rapid appraisal was administered to 25 family respondents on one day. On the following day, team members administered the questionnaire to 25 nurses who had not had any direct involvement in the design process. All responses $(n=50)$ were collated and analysed using mean and median scores. Thematic analysis of the open-ended questions yielded additional insights.

The rapid appraisal response rate was high as respondents were approached directly and then given the opportunity to participate and then respond. Five of the 50 respondents had not seen or noticed any new signs. Response rates scored all items as more than four out of five on the Likert scale. No parents answered the open-ended question, indicating that the team required different ways of encouraging parents to respond to the questionnaire.

Thematic analysis of responses to Item 5 by the nurse respondents indicated that the signs improved the physical appearance of their unit: 'it looks nice'. Another theme was that the signs seemed to decrease the time nurses spent repeating directions and it was felt that this could decrease the levels of nurses' frustration: 'I don't need to say that door is locked over and over again'.

\section{Ethical considerations}

Ethical approval for a facility-wide improvement programme using action research was received from the Research Ethics Committee of the Faculty of Health Sciences, University of Cape Town (REC REF 149/2005) and written permission for the study was obtained from the Head of Nursing Services at the hospital.

\section{Recruitment procedures, informed consent and data protection}

Data gathering during the rapid appraisal was done by three operational team members who administered the family questionnaires wearing unidentifiable, casual clothing; they approached as many family respondents as possible

\section{We understand that a child's hospital visit} is always stressful!

Please talk to us about your concerns.

$$
\text { 'n Hospital besoek is altyd stresvol! }
$$

Praat gerus met ons oor enige vrese

$$
\text { (of vrae). }
$$

\section{Siyakwazi ukuba ukutyelela esibhedlele kungabanzima. \\ Sicela uthethe nathi nangantoni na.}

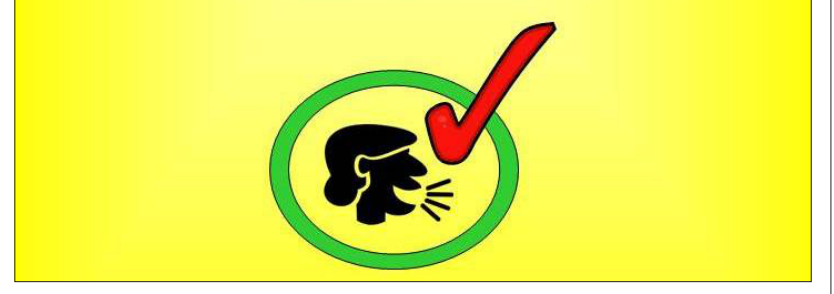

FIGURE 2: Signage example.

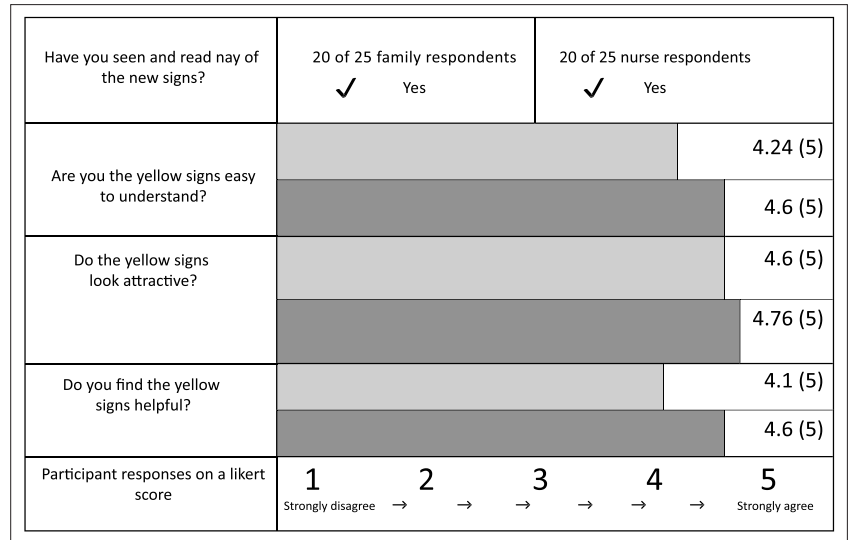

FIGURE 3: Rapid appraisal results - mean (median) scores represented. 
in a three-hour period. They explained to participants the aim of the survey, that there would be no direct benefit as a result of their participation, that the respondent could withdraw at any time and that their involvement or noninvolvement would not affect the care that they or their child would receive. Parents were not required to provide their names, so all results remained confidential and anonymous. The operational team members obtained voluntary verbal consent and administered the questionnaire by asking five questions and recording the responses.

\section{Discussion}

The review and development of signage was conducted at the tertiary children's hospital in Cape Town using a participative action research cycle. Nurses' active involvement and, later, positive reception of the redesigned and standardised signage was evident in their reflections. This was confirmed in the rapid appraisal survey responses. In their responses to open-ended questions, nurses shared that the new signage impacted positively on their environment and indirectly on their relationship with families, as families asked less repetitive questions, thereby decreasing nurses' frustration.

The review process revealed how instructions and tone used on signage reflected approaches to families. Nurses realised the role of standardised information for parents; numerous conversations were generated regarding how words used on signage affect communication with families.

This project followed recommendations made by Coetzee (2010) that health professionals be assisted in evaluating their own practice through an inclusive and participatory process, in order to shift practice toward family-friendly care. The outcomes of the rapid appraisal indicated that parents found the new, standardised signs to be attractive and helpful in facilitating their journey through the facility, which presumably decreased some of their stress.

Multilingual, family-friendly signs contribute to improving parent's access to health information and their capacity to use this information effectively, which the World Health Organization maintains is critical with regard to empowerment in healthcare settings (World Health Organization 2009).

The redesign and standardisation of hospital signage reduced the number of signs displayed in the hospital, improved their appearance and increased their effectiveness. Standardisation made signage easier to locate and understand and conveyed a more family-friendly attitude. The simplification of messages and consistent use of graphics made signage more accessible to parents of all literacy levels.

\section{Limitations of the study}

The rapid appraisal questionnaire was written and administered in English; some of the Afrikaans and isiXhosa speaking parents might have encountered difficulty expressing their thoughts in English and therefore did not answer the open-ended question. Parents and children were not enrolled to participate in the earlier part of the process of design of signage and, as the essential users of the signs, this poses a clear limitation.

\section{Recommendations}

This practice improvement study reviewed current signage in a South African tertiary children's hospital. A team of nurses identified the need for improved signage to more effectively convey essential information, to save time and to support family-centred care. Using a participative approach, they designed a standardised template for multilingual signs, augmented with graphic elements to facilitate wayfinding and convey essential information. A review of signage may be a similarly eye-opening exercise for nurses in other healthcare settings and a potential method of promoting more family-friendly environments for shifting the quality of healthcare encounters for parents.

The study fills a gap in the literature regarding the participative design and implementation of healthcare facility signage in low-resourced settings and where low literacy is common. Questions for future research include: is family-friendly signage cost-effective? How has family-friendly signage shifted the tone of healthcare encounters? Do families benefit by having signs in three languages? A similar process could be used to improve information that is intended to prepare parents and children for complex procedures.

Future practice improvement process should intentionally engage parents and children in improvement design and measure patient and family experience.

Rapid appraisal tools should also be available in Afrikaans and isiXhosa. It may be beneficial in future studies to include an independent, trilingual data-gatherer in the evaluation phase. Working with nurses in busy clinical settings poses challenges to their active participation, but their clear knowledge of the day-to-day situations in clinical facilities is vital to understanding complex clinical problems. Finding innovative ways of engaging these participants remains an imperative in shaping their clinical practice environments.

\section{Conclusion}

The participative study design was valuable in engaging nurses around a relatively non-threatening issue in their day-to-day practice setting. The inclusion of nurses in describing the current situation enabled them to verbalise their response to the number and state of signs that existed. The authoritative tone of many signs became more evident when considered through a 'family-friendly' lens. The tone of the numerous makeshift signs may well have been indicative of an unrecognised source of frustration for these nurses working in a busy children's hospital, undergoing continual refurbishments. The participative redesign of signage resulted in a sense of ownership of the signs amongst 
the nurses and created pride in their contribution toward creating a more family-friendly environment in the hospital.

A process initiated by a nursing directive, that included hospital management, also ensured their support throughout and wide acceptance of the project outcomes.

\section{Acknowledgements}

The authors wish to thank the families who participated in the study, the head of nursing services, the management and nurses of the tertiary children's hospital for their support in embracing the process and accepting the new signage that was implemented.

\section{Competing interests}

The authors declare that they have no financial or personal relationship(s) that may have inappropriately influenced them in writing this article.

\section{Authors' contributions}

M.C. (University of Cape Town) is the Head of the Child Nurse Practice Development Initiative and was responsible for study design. A.L. (University of Cape Town) and A.V. (University of Cape Town) were responsible for implementation, data collection and analysis. All authors contributed to writing the manuscript.

\section{References}

Annett, H. \& Rifkin, S., 1988, Improving urban health: Guidelines for rapid appraisal to assess community health needs, a focus on health improvements for low-income urban areas, WHO/SHS/NHP/88.4, viewed 02 June 2014, from http://apps.who. int/iris/bitstream/10665/62112/1/WHO_SHS_NHP_88.4.pdf?ua=1

Arthur, P. \& Passini, R., 2002, Wayfinding: People, signs, and architecture, 10th anniversary edn., Focus Strategic Communications, Oakville, ON.

Coetzee, M., 2010, Towards child-and family-friendly health services, South African Child Gauge 2009/2010, viewed 02 August 2013, from http://www.ci.org.za/ depts/ci/pubs/pdf/general/gauge2009-10/sa_child_gauge09-10_child_friendly services.pdf

Coghlan, D. \& Casey, M., 2001, 'Action research from the inside: Issues and challenges in doing action research in your own hospital', Journal of Advanced Nursing 35(5), 674-682. http://dx.doi.org/10.1046/j.1365-2648.2001.01899.x

Commodari, E., 2010, 'Children staying in hospital: A research on psychological stress of caregivers', Italian Journal of Pediatrics 36, 40, 9 pages.

Cooper, R., 2010, 'Successful signage: how hospitals have solved wayfinding challenges', Health Facilities Management, viewed 24 June 2014, from http:// www.hfmmagazine.com/inc-hfm/pdfs/2010/10HFM11_FEA_plan.pdf
Cooper, R. \& Smith, R., 2004, 'Sign language: Wayfinding design requires a team approach', Health Facilities Management 17(9), 24-28.

Frazier, A., Frazier, H. \& Warren, NA., 2010, 'A discussion of family-centered care within the pediatric intensive care unit', Critical Care Nursing Quarterly 33(1), 82-86. http://dx.doi.org/10.1097/CNQ.0b013e3181c8e015

Houts, P.S., Doak, C.C., Doak, L.G. \& Loscalzo, M.J., 2006, 'The role of pictures in improving health communication: A review of research on attention, comprehension, recall, and adherence', Patient Education and Counseling 61(2), 173-190. http://dx.doi.org/10.1016/j.pec.2005.05.004

IBM Global Work/Life Fund, 2004, What is family-friendly child care and why does it matter? What parents and providers say - and the implications for quality care. Executive summary, viewed 10 June 2014, from http://www.abcdependentcare. com/docs/Family-Friendly-Project-Executive-Summary.pdf

InstituteforHealthcare Improvement, 2003, 'Thebreakthroughseries:IHI'scollaborative model for achieving breakthrough improvement', IHI Innovation Series white paper, viewed 18 April 2014, from http://www.ihi.org/resources/Pages/IHIWhitePapers/ viewed 18 April 2014, from http://wWw.ihi.org/resources/Pages/IHIWhitePapers/ TheB
aspx

Jackson, R., Baird, W., Davis-Reynolds, L., Smith, C., Blackburn, S. \& Allsebrook, J., 2008, 'Qualitative analysis of parents' information needs and psychosocial experiences when supporting children with health care needs' Health Information and Libraries Journal 25(1), 31-37. http://dx.doi.org/10.1111/j.14711842.2007.00736.x

Kain, Z.N., Mayes, L.C., O'Connor, T.Z. \& Cicchetti, D.V., 1996, 'Preoperative anxiety in children. Predictors and outcomes', Archives of Pediatric \& Adolescent Medicine 150(12), 1238-1245. http://dx.doi.org/10.1001/archpedi.1996.02170370016002

Mackenzie, J., Tan, P-L., Hoverman, S. \& Baldwin, C., 2012, 'The value and limitations of Participatory Action Research methodology', Journal of Hydrology 474, 11-21. http://dx.doi.org/10.1016/j.jhydrol.2012.09.008

McKenna, K. \& Scott, J., 2007, 'Do written education materials that use content and design principles improve older people's knowledge?', Australian
Occupational Therapy Journal 54(2), 103-112. http://dx.doi.org/10.1111/j.1440Occupational Therapy
1630.2006.00583.x

Mollerup, P., 2009, 'Wayshowing in hospital', Australasian Medical Journal 1(10), 112-114.

Montpetit, M., 2013, How hospitals talk to patients: Creating clear signage for a positive patient experience, viewed 12 August 2014, from https://www. facilitycare.com/building-blocks/signage/how-hospitals-talk-patients-creatingclear-signage-positive-patient

Murray, S.A., 1999, 'Experiences with "rapid appraisal" in primary care: Involving the public in assessing health needs, orientating staff, and educating medica students', British Medical Journal 318(7181), 440-444. http://dx.doi.org/10.1136/ bmj.318.7181.440

Olshansky, E., Sacco, D., Braxter, B., Dodge, P., Hughes,E., Ondeck, M. et al., 2005 , 'Participatory action research to understand and reduce health disparities', Nursing Outlook 53(3), 121-126. http://dx.doi.org/10.1016/j.outlook.2005.03.002

Reason, P. \& Bradbury, H. (eds.), 2001, Handbook of action research: Participative inquiry and practice, viewed 24 October 2013, from http://faculty.mu.edu.sa/ inquiry and practice, viewed 24 October 2013, from http://faculty.n
public/uploads/1346012794.621handbook_of action_research.pdf

Rousek, J.B. \& Hallbeck, M.S., 2011, 'Improving and analyzing signage within a healthcare setting', Applied Ergonomics 42(6), 771-784. http://dx.doi. org/10.1016/j.apergo.2010.12.004

Scott, A., 2004, 'Managing anxiety in ICU patients: The role of pre-operative information provision', Nursing in Critical Care 9(2), 72-79. http://dx.doi. org/10.1111/j.1478-5153.2004.00053.x

Statistics South Africa, 2012, Social profile of vulnerable groups in South Africa, 2002 2011, viewed 27 August 2013, from http://www.statssa.gov.za/publications/ statsdownload.asp?PPN=Report-03-19-00\&SCH=5399

World Bank, 2004, Monitoring \& evaluation: Some tools, methods \& approaches, viewed 02 October 2013, from http://www-wds.worldbank.org/external/default/
WDSContentServer/WDSP/IB/2006/02/15/000012009 20060215093620/ WDSContentServer/WDSP/IB/2006/02/15/000012009_2006
Rendered/PDF/246140UPDATED01s1methods1approaches.pdf

World Health Organization, 2009, Health Promotion, Track 2: Health literacy and health behaviour, viewed 16 July 2014, from http://www.who.int/healthpromotion/ conferences/7gchp/track2/en/ 